\title{
Ultrastructure of Spinal Relay of Hypoglossal Afferents to the Parabrachial Nucleus
}

\author{
By
Shigetoshi MIYOSHI, Xiao Hua CHEN, Masahiro ITOH, Takanori MIKI, Wei SUN and Yoshiki TAKEUCHI

Department of Anatomy, Kagawa Medical School, 1750-1 Ikenobe, Miki-cho, Kita-gun, Kagawa 761-07, Japan

- Received for Publication, April 19, $1995-$

Key Words: Hypoglossal nerve, Sensory fibers, Parabrachial nucleus, Cervical spinal cord, Lamina I

\begin{abstract}
Summary: Wheat germ agglutinin-conjugated horseradish peroxidase (WGA-HRP) injection into the hypoglossal nerve mainly resulted in retrograde labeling in the superior ganglia of the glossopharyngeal and vagal nerves ipsilaterally. Anterogradely labeled fibers were found in lamina I of the ipsilateral upper cervical spinal cord with a few distribution to laminae IV-V and VII-VIII. WGA-HRP injection into the PBN revealed intensive labeling of lamina I neurons of the upper cervical spinal cord ipsilaterally. These light microscopic observations appear to indicate the hypoglossal sensory inputs to the PBN through the spinal cord. In order to investigate the synaptic nature of this spinal relay, electron microscopic observations were carried out on lamina I of the first and second cervical spinal cord after cutting the hypoglossal nerve and WGA-HRP injection into the PBN in the same animal. The spinoparabrachial projection neurons were demonstrated to show a low cytoplasmic/nuclear ratio and have an oval or deeply indented nucleus with a centrally located nucleolus. Furthermore, dark and light type degenerating fibers were observed to make synaptic contacts with HRP-labeled somata and dendritic profiles.
\end{abstract}

Recent anatomical data have made possible a better understanding of the neural organization with respect to the motor and autonomic components in the hypoglossal nerve ${ }^{10,32,33)}$. Concerning sensory components, previous studies mainly focused on the location of ganglion cells ${ }^{4,31,37)}$. Subsequent studies revealed the central distribution of sensory fibers in the hypoglossal nerve utilizing transganglionic transport of $\mathrm{HRP}^{20,28)}$. In these works, lamina I of the upper cervical spinal cord was demonstrated to be one of the major target of the afferents. However, it is likely that there are significant lacunae about the secondary pathway of the sensory information. In particular, ascending projections from lamina I remain to be ascertained.

Lamina I, as well as marginal layer of the trigeminal spinal caudal subnucleus, contains c-fos immunoreactive neurons which are considered to play an important role in modulatory mechanisms related to nociception ${ }^{9,11,17,34)}$. On the other hand, lamina I neurons are reported to respond exclusively to noxious stimuli and send axons to the parabrachial nucleus $(\mathrm{PBN})^{13)}$. Taken together, these anatomical and physiological findings seem to suggest that sensory information in the hypoglossal nerve is conveyed to the PBN through lamina I of the cervical spinal cord. Therefore, the present study was done to elucidate the synaptic morphology of the spinal relay on lamina I which connects between the primary afferent fibers in the hypoglossal nerve and the PBN in the cat.

\section{Materials and Methods}

Experiments were performed on nineteen cats weighing $0.7-4.6 \mathrm{~kg}$ and anesthetized with intraperitoneal injections of pentobarbital soda $(40 \mathrm{mg} / \mathrm{kg})$. The anesthesia was maintained through small doses of pentobarbital administered intraperitoneally.

\section{Light microscopic experiments}

One side of the neck was opened by a longitudinal incision and the hypoglossal nerve was exposed widely around the common carotid artery. After cutting the superior radix of the ansa cervicalis. 
$2-5 \mu$ l of $0.2 \%$ WGA-HRP (Toyobo) dissolved in sterile $0.9 \%$ saline were injected into the hypoglossal nerve using a $10 \mu \mathrm{l}$ Hamilton microsyringe (11 cats). In the other experiment, $0.02-0.03 \mu$ l of $5 \%$ WGAHRP were injected stereotaxically into the lateral portion of the PBN using a glass micropipette (tip diameter: $50-60 \mu \mathrm{m})$ attached to a $1-\mu \mathrm{l}$ Hamilton microsyringe ( 3 cats). After a survival period of $2-3$ days, the animals were deeply anesthetized again and sacrificed by perfusion through the ascending aorta with $0.1 \mathrm{M}$ phosphate buffer ( $\mathrm{pH} 7.4)$ followed by a fixative containing $8 \%$ formalin in $0.1 \mathrm{M}$ phosphate buffer. The brain and spinal cord were removed from the skull immediately together with the trigeminal and geniculate ganglia, superior and inferior ganglia of the glossopharyngeal and vagal nerves, and $\mathrm{C} 1-\mathrm{C} 3$ spinal ganglia on the side ipsilateral to the injection. The lower brain stem through the hypoglossal nucleus, spinal cord and each ganglion were cut transversely at $60 \mu \mathrm{m}$-thickness on the freezing microtome. All sections were processed for the demonstration of HRP reaction product according to the tetramethyl benzidine (TMB) protocol of Mesulum $^{18)}$ and were counterstained with neutral red.

\section{Electron microscopic experiments}

The hypoglossal nerve was cut at the portion distal to the superior radix of the ansa cervicalis, followed 1-2 weeks later by injection of $0.02-$ $0.03 \mu \mathrm{l}$ of $5 \% \mathrm{WGA}-\mathrm{HRP}$ into the lateral portion of the $\mathrm{PBN}$ on the side ipsilateral to dissection (3 cats). After a survival period of $2-3$ days, the animals were sacrificed by perfusion with $0.1 \mathrm{M}$ phosphate buffer followed by a fixative of $1 \%$ paraformaldehyde and $2.5 \%$ glutaraldehyde in $0.1 \mathrm{M}$ phosphate buffer (pH 7.4). In order to confirm the injections of WGAHRP into the PBN and hypoglossal nerve, $60 \mu \mathrm{m}$ thick frozen sections through the lower brain stem containing the PBN and hypoglossal nerve were cut transversely and reacted with TMB. $200 \mu \mathrm{m}$-thick transverse sections through the $\mathrm{C} 1$ and $\mathrm{C} 2$ spinal cord were made. These sections were immersed in $2 \%$ ammonium molybdate, dissolved in a $5 \%$ solution of $0.2 \mathrm{M}$ acetate buffer ( $\mathrm{pH} 3.3$ ) for $30 \mathrm{~min}$, to stabilize the HRP reaction products according to the method reported previously ${ }^{27}$. Then, the sections were postfixed in buffered $1 \%$ osmium tetroxide for 2 hours, block-stained with saturated uranyl acetate for 1 hour, dehydrated in a graded acetone series and embedded in Epon. Lamina I of the $\mathrm{C} 1$ and $\mathrm{C} 2$ spinal cord was identified on $1 \mu \mathrm{m}$-thick sections stained with toluidine blue. Ultrathin sections through lamina I were observed without further staining in a JEOL $200 \mathrm{CX}$ electron microscope.

\section{Results}

\section{Light microscopic experiments}

WGA-HRP injection into the hypoglossal nerve resulted in retrograde labeling through the whole of the hypoglossal nucleus (Fig. 1). With respect to labeling in the ganglia, a lot of neurons in the superior ganglia of the glossopharyngeal and vagal nerves were labeled with HRP ipsilaterally (Figs. 3 and 4). A few labeled neurons occurred in the inferior ganglion of the vagal nerve and spinal ganglion of the $\mathrm{C} 1$ segment. Fewer labeled neurons were found sporadically in the mandibular branch of the trigeminal ganglion, inferior ganglion of the glossopharyngeal nerve and spinal ganglia of the $\mathrm{C} 2$ and $\mathrm{C} 3$ segments. There was no labeling in the ophthalmic and maxillar branches of the trigeminal ganglion and geniculate ganglion. Central projections of the hypoglossal nerve were demonstrated utilizing transganglionic transport of HRP. HRP-labeled glossopharyngeal and vagal afferent fibers entered into the brain stem from the lateral surface at the level from the facial nucleus to the inferior olivary nucleus ipsilaterally. These fibers were observed to distribute to the marginal layer of the spinal trigeminal caudal subnucleus and the solitary regions lateral and medial to the solitary tract across the dorsal portion of the spinal trigeminal tract. Other target areas of the fibers were found in the lateral region of the medial cuneate nucleus and commissural nucleus. From these glossopharyngeal and vagal fibers distributing to various areas in the brain stem, labeled fiber bundles were observed to descend through the dorsal portion of the spinal trigeminal tract. Labeled fibers could be tarced as far as the $\mathrm{C} 3$ segment with a gradual decrease of labeling. It was of particular interest that in the cervical spinal cord labeling was exclusively confined to lamina I with a few distribution to laminae IV-V and VII-VIII ipsilaterally (Fig. 5).

In order to identify the cells of origin of the spinoparabrachial pathway, WGA-HRP was injected into the PBN. The site of injection was confined to the lateral portion of the PBN (Fig. 2). This injection resulted in retrograde labeling in lamina I with the ipsilateral predominance. Labeled neurons were characterized by the morphology of spindle or triangular shape and long dendrites extending mediolaterally (Fig. 6). This labeling was most conspicuous at the $\mathrm{C} 1$ segment. A few labeled neurons were also observed to be present bilaterally in the spinal trigeminal caudal subnucleus, solitary nucleus, medullary reticular formation and laminae IV-V and VII in the upper cervical spinal cord. 


\section{Electron microscopic experiments}

After transection of the hypoglossal nerve, WGAHRP was injected into the PBN in the same animal. The tracer enzyme was largely confined to the lateral portion of the PBN although a slight diffusion occurred into the ventral and medial portions of the PBN. $1 \mu \mathrm{m}$-thick sections were prepared prior to electron microscopic observation. The region of lamina I, containing primary afferent fibers in the hypoglossal nerve and spinoparabrachial projection neurons, was identified under the light microscope. In the neuropil of lamina I, ultrathin sections revealed the typical morphology of transganglionic degenerating afferent fibers and retrograde labeling of somata and dendritic profiles. HRP-labeled neurons showed a low cytoplasmic/nuclear ratio and had an oval or deeply indented nucleus with a centrally located nucleolus. The relatively developed cytoplasm contained many electron-dense HRP reaction products (Figs. 7 and 8). These products were best visualized when lead citrate staining was omitted. Degenerating axon terminals were identified as the dark type which was characterized by irregular shape, dark matrix and swollen mitochondria (Figs. 9-13). The majority of these terminals had a long axis ranging from 0.8 to $2.1 \mu \mathrm{m}$ and frequently contained both small round and large dense cored vesicles (Figs. 9 and 12). A few degenerating terminals were classified as the light type which was mainly characterized by accumulation of small round vesicles and light matrix (Fig. 10). These degenerating terminals of the dark and light types made synaptic contacts with HRP-labeled somata (Figs. 9 and 10) and dendritic profiles of $2.5-4.1 \mu \mathrm{m}$ in diameter (Figs. 11 and 12). Fewer terminals were observed to synapse upon spine-like protrusions less than $1 \mu \mathrm{m}$ (Fig. 14).

\section{Discussion}

With respect to the location of the sensory cells of afferent fibers in the hypoglossal nerve, previous studies led to varied conclusions. Morphologically, the sensory cells were demonstrated to locate along the course of the hypoglossal nerve $\mathrm{e}^{22,23,31,37)}$. In the other reports these cells were described to be present in the spinal ganglia of the cervical spinal cord ${ }^{4,14,35}$, inferior $^{30,37)}$ and superior ganglion ${ }^{4,21)}$ of the vagal nerve. Further anatomical studies have revealed the additional labeling of sensory cells in the trigeminal ganglion and superior ganglion of the glossopharyngeal nerve ${ }^{20,28)}$. On the other hand, physiologically, the existence of the afferent fibers was also proposed by recording of afferent impulses in the isolated filaments of the hypoglossal nerve ${ }^{2,6)}$, stimulation of the hypoglossal nerve evoked vascular reac- tions ${ }^{8,30)}$ and reflex activation of the facial ${ }^{16,29,36)}$ and laryngeal muscles ${ }^{25,36)}$. This variety of anatomical and physiological findings apparently implies that there are various pathways of the afferent fibers in the hypoglossal nerve. However, considering the degree of labeling in ganglia, the glossopharyngeal and vagal nerves appear to give rise to major pathway of the afferents.

Central distribution of the afferent fibers in the hypoglossal nerve was elucidated exactly utilizing transganglionic transport of $\mathrm{HRP}^{20,28)}$. In these reports it is of particular interest that the fibers distribute exclusively to lamina I of the upper cervical spinal cord, because lamina $I$ is considered to be the significant site for receiving nociceptive informations ${ }^{5,11,15)}$. In fact, expression of c-fos, enkephalin and substance $P$ is found in lamina $I$ dorsal horn and marginal layer of spinal trigeminal caudal subnucleus following stimulation of cutaneous sensory afferents ${ }^{9,11,17,26,34)}$. In the present study, ultrastructure of lamina I frequently revealed terminals which contained large dense cored vesicles. These vesicles in terminals are considered to be associated with the presence of biogenic amines and peptides as the neurotransmitter ${ }^{3)}$ and play an important role in transmission of pain ${ }^{26)}$.

The present light and electron microscopic observations revealed the morphological characteristics of spinoparabrachial projection neurons. These neurons in lamina I, which are spindle or triangular in shape and have 2-3 long dendrites extending mediolaterally, are quite similar to those sending axons to the thalamus and hypothalamus ${ }^{12,13)}$. It is of interest that the pontine termination of these neurons is exclusively located to the lateral portion of the PBN which participates in regulation of cardiovascular ${ }^{7,19)}$, respiratory ${ }^{24)}$ and grooming activity ${ }^{1)}$. In the recent study, greater than $80 \%$ of neurons in lamina I projecting to the thalamus were demonstrated to have axon collaterals terminating in the $\mathrm{PBN}^{12)}$. Furthermore, physiological data led to conclusions that neurons in lamina I projecting to the lateral portion of the PBN respond exclusively to noxious stimulation ${ }^{13)}$. The present study provided an anatomical substrate for spinal relay of afferents of nociceptive information in the hypoglossal nerve to the midbrain including the PBN.

\section{Acknowledgements}

The authors would like to thank Mr. Wakashi Nagata for technical assistance. 


\section{References}

1) Berntson GG. Attack, grooming, and threat elicited by stimulation of the pontine tegmentum in cats. Physiol Behav 1972; 11:81-87.

2) Blom S. Afferent influences on tongue muscle activity. Acta Physiol Scand 1960; 49 (Suppl. 170):1-97.

3) Bloom FE. Ultrastructural identification of catecholaminecontaining central synaptic terminals. J Histochem Cytochem 1973; 21:333-348.

4) Chibuzo GA and Cummings JF. The origins of the afferent fibers to the lingual muscles of the dog, a retrograde labeling study with horseradish peroxidase. Anat Rec 1981; 200:95-101.

5) Christensen BN and Perl ER. Spinal neurons specifically excited by noxious or thermal stimuli: marginal zone of the dorsal horn. J Neurophysiol 1970; 33:293-307.

6) Cooper S. Afferent impulses in the hypoglossal nerve on stretching the cat's tongue. J Physiol (Lond.) 1954; 126:32P.

7) Coote JH. Hilton SM and Zbrozyna W. The ponto-medullary area integrating the defense reaction in the cat and its influence on muscle blood flow. J Physiol (Lond.) 1973; 229:257-274.

8) Downman CBB. Afferent fibers of the hypoglossal nerve. J Anat $1939 ; 73: 387-395$.

9) Draisci G. and Iadarola MJ. Temporal analysis of increases in c-fos, preprodynorphin and preproenkephalin mRNA in rat spinal cord. Molecular Brain Res 1989; 6:31-37.

10) Fukui $H$, Hayakawa $T$, Itoh $M$, Fujimoto $Y$, Nishimura $Y$ and Takeuchi $Y$. The superior cervical ganglion: origin of sympathetic fibers in the facial and hypoglossal nerves in the cat. Brain Res Bull 1992; 28:811-815.

11) Hunt SP, Pini A and Avan G. Induction of c-fos-like protein in spinal cord neurons following sensory stimulation. Nature 1987; 328:632-634.

12) Hylden JLK, Anton F and Nahin RL. Spinal lamina I projection neurons in the rat: collateral innervation of parabrachial area and thalamus. Neurosci 1989; 28:27-37.

13) Hylden JLK. Hayashi H, Dubner K and Bennett GJ. Physiology and morphology of the lamina I spinomesencephalic projection. J Comp Neurol 1986; 247:505-515.

14) Kendall B, Crobin KB and Harrison F. The sensory innervation of the spinal accessory and tongue musculature in the rhesus monkey. Brain 1939; 62:191-197.

15) Light AR, Trevino DL and Perl ER. Morphological features of functionally defined neurons in the marginal zone and substantia gelatinosa of the spinal dorsal horn. J Comp Neurol 1979; 186:151-172.

16) Lindquist $C$ and Martensson $A$. Reflex responses induced by stimulation of hypoglossal afferents. Acta Physiol Scand 1969; 77:234-240.

17) Menetrey D, Gannon A, Levine JD and Basbaum AI Expression of $\mathrm{c}$-fos protein in interneurons and projection neurons of the rat spinal cord in response to noxious somatic, articular, and visceral stimulation. J Comp Neurol 1989; 285:177-195.

18) Mesulam M-M. Tetramethyl benzidine for horseradish peroxidase ncurohistochemistry: a non-carcinogenic blue reaction-product with superior sensitivity for visualizing neural afferents and efferents. J Histochem Cytochem 1978; 26:106-117.

19) Mraovitch S, Kumada $M$ and Reis DJ. Role of the nucleus parabrachialis in cardiovascular regulation in cat. Brain Res
1982; 232:57-75.

20) Nazruddin S, Suemune S, Shirana $Y$, Yamauchi K. and Shigenaga $Y$. The cells of origin of the hypoglossal afferent nerves and central projections in the cat. Brain Res 1989; 490:219-235.

21) Neuhuber W. and Mysicka A. Afferent neurons of the hypoglossal nerve of the rat as demonstrated by horseradish peroxidase tracing. Anat Embryol (Berl.) 1980; 158:349-360.

22) Pearson AA. Sensory type neurons in the hypoglossal nerve. Anat Rec 1943; 85:365-275.

23) Pearson AA. Further observations on the intramedullary sensory type neurons along the hypoglossal nerve. J Comp Neurol 1961; 82:93-100.

24) Riche $D$, Denavit-Saubie $M$ and Champagnat J. Pontine afferents to the medullary respiratory system: anatomofunctional correlation. Neurosci Lett 1979; 13:151-155.

25) Sauerland EK and Mizuno N. Hypoglossal nerve afferents: elicitation of a polysynaptic hypoglossolaryngeal reflex. Brain Res 1968; 10:256-258.

26) Senba E, Yanaihara $\mathrm{C}$, Yanaihara $\mathrm{N}$ and Tohyama $\mathrm{M}$. Colocalization of substance $P$ and Met-enkephalin-Arg-GlyLeu in the intraspinal neurons of the rat, with special reference to the neurons in the substantia gelatinosa. Brain Res 1988; 453:110 - 116 .

27) Takeuchi $Y$, Fukui $Y$, Ichiyama $M$, Miyoshi $S$ and Nishimura $Y$. Direct amygdaloid projections to the superior salivatory nucleus: a light and electron microscopic study in the cat. Brain Res Bull 1991; 27:85-92.

28) Takeuchi $Y$, Hayakawa T, Ozaki HS, Kito J, Satoda T and Matsushima R. Afferent fibers in the hypoglossal nerve: a horseradish peroxidase study in the cat. Brain Res Bull 1990; 24:81-87.

29) Tanaka T. Afferent projections in the hypoglossal nerve to the facial neurons of the cat. Brain Res 1975; 99:140-144.

30) Tarkhan AA and Abou-El-Naga I. Sensory fibers in the hypoglossal nerve. J Anat 1947; 81:23-32.

31) Tarkhan AA and Abd El Malek S. On the presence of sensory nerve cells on the hypoglossal nerve. J Comp Neurol 1950; 93:219-228.

32) Uemura $M$, Matsuda $K$, Kume $M$, Takeuchi $Y$, Matsushima $\mathrm{R}$ and Mizuno N. Topographical arrangement of hypoglossal motoneurons: an HRP study in the cat. Neurosci Lett 1979; 13:99-104.

33) Uemura-Sumi $M$, Mizuno $N$, Nomura $S$, Iwahori $N$, Takeuch $\mathrm{Y}$ and Matsushima $\mathbf{R}$. Topographical representation of the hypoglossal nerve branches and tongue muscles in the hypoglossal nucleus of macaque monkeys. Neurosci. Lett 1981; 22:31-35.

34) Wang LG, Li HM and Li JS. Formalin induced fos-like immunoreactive neurons in the trigeminal spinal caudal subnucleus project to contralateral parabrachial nucleus in the rat. Brain Res 1994; 649:62-70.

35) Yee J, Harrison F and Corbin KB. The sensory innervation of the spinal accessory and tongue musculature in the rabbit. $J$ Comp Neurol 1939; 70:305-314.

36) Zapata PG and Torrealba G. Reflex effects evoked by stimulation of hypoglossal afferent fibers. Brain Res 1988; 445:19-29.

37) Zimny $R$, Sobusiak $T$ and Matlosz $Z$. The afferent components of the hypoglossal nerve. J Hirnforsch 1970; 12:83-100. 

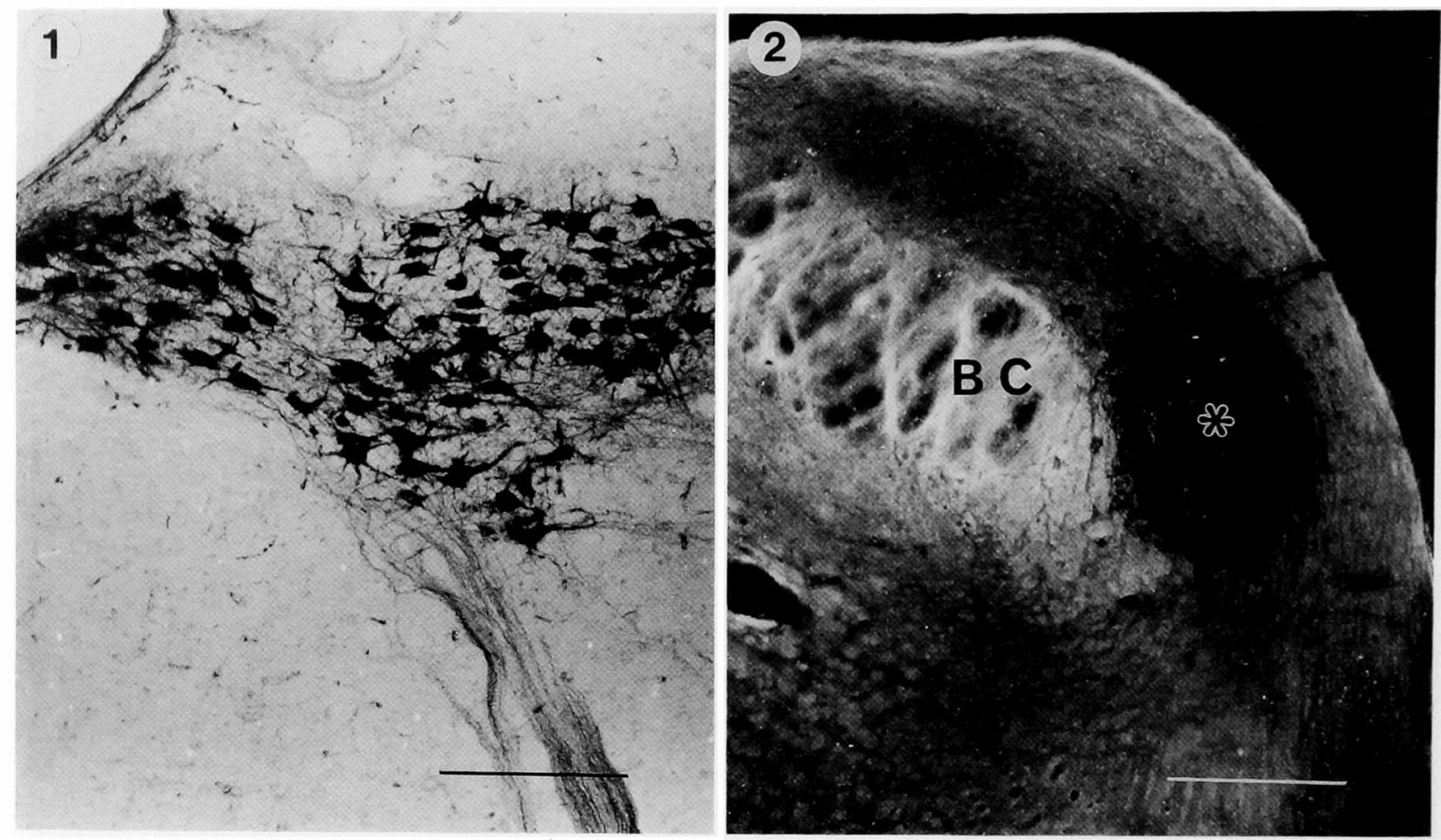

Abbreviations

BC brachium conjunctivum

DAT degenerating axon terminal

HRP horseradish peroxidase

NUCL nucleus
IXn glossopharyngeal nerve

$X n$ vagal nerve

I-IV laminae I-IV of spinal cord

\section{Explanation of Figures}

\section{Plate I}

Figs. 1 and 2. Photomicrographs of retrogradely labeled neurons in the hypoglossal nucleus after WGA-HRP injection into the hypoglossal nerve (Fig. 1) and the site of WGA-HRP injection into the PBN (Fig. 2). Note that the tracer enzyme is exclusively confined to the lateral portion of the PBN (asterisk). Calibration bars in Fig. $1=200 \mu \mathrm{m}$, Fig. $2=0.5 \mathrm{~mm}$. 
Plate II
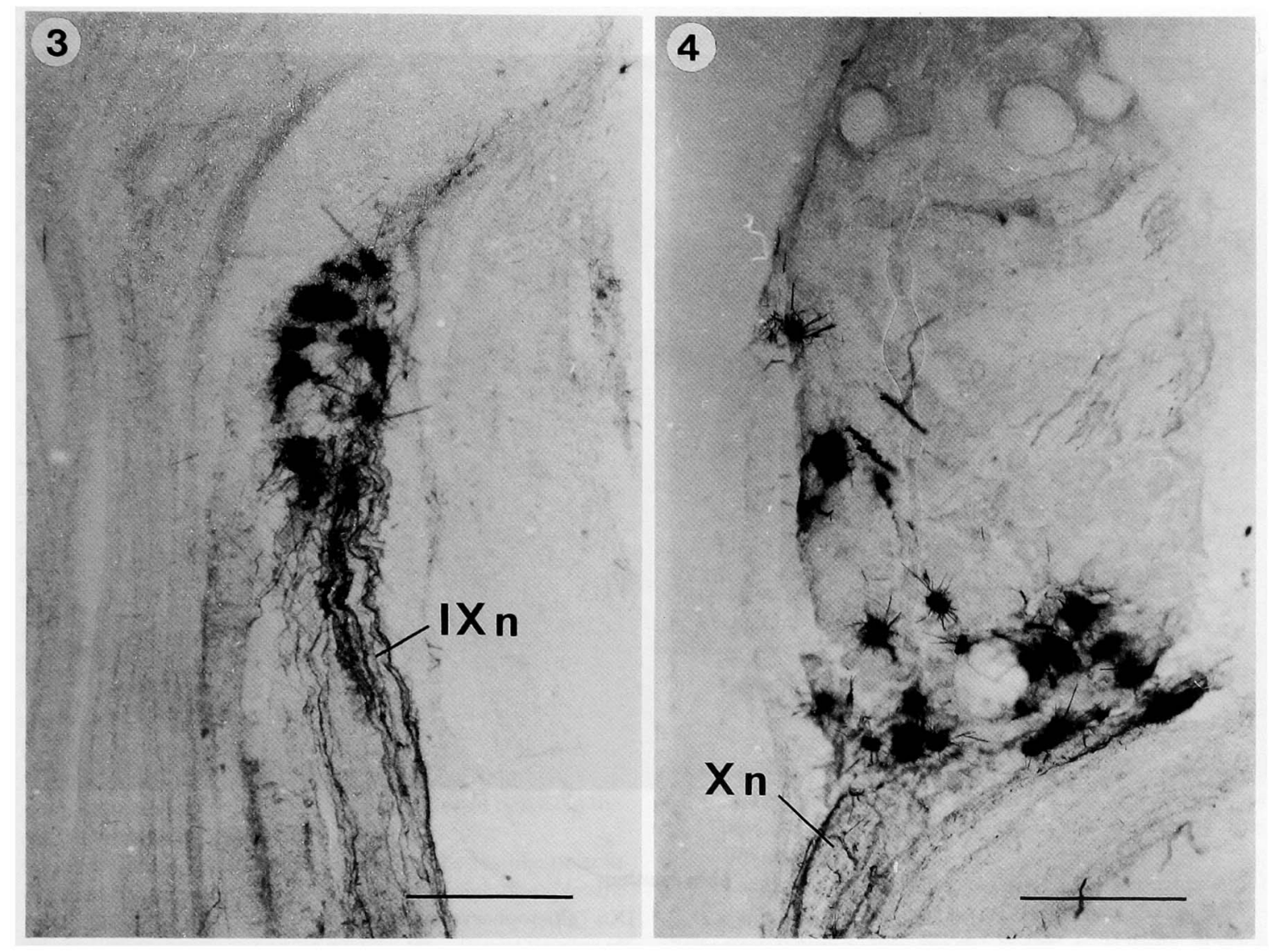

\section{Plate II}

Figs. 3 and 4. Photomicrographs of retrogradely labeled nuerons in the superior ganglia of the glossopharyngeal (Fig. 3) and vagal nerve (Fig. 4). Calibration bars in Figs. 3 and $4=200 \mu \mathrm{m}$.

\section{Plate III}

Figs. 5-7. Photomicrographs of HRP-labeled fibers (Fig. 5) and spinoparabrachial projection neurons (Fig. 6) which were exclusively confined to lamina I of the $\mathrm{C} 1$ spinal cord. Note that retrogradely labeled neurons were spindle or triangular in shape and had two or three dendrites extending mediolaterally (Fig. 7). Spinoparabrachial projection neurons in Fig. 6 (framed area) are magnified in Fig. 7. Calibration bars in Figs 5 and $6=300 \mu \mathrm{m}$, in Fig. $7=100 \mu \mathrm{m}$. 

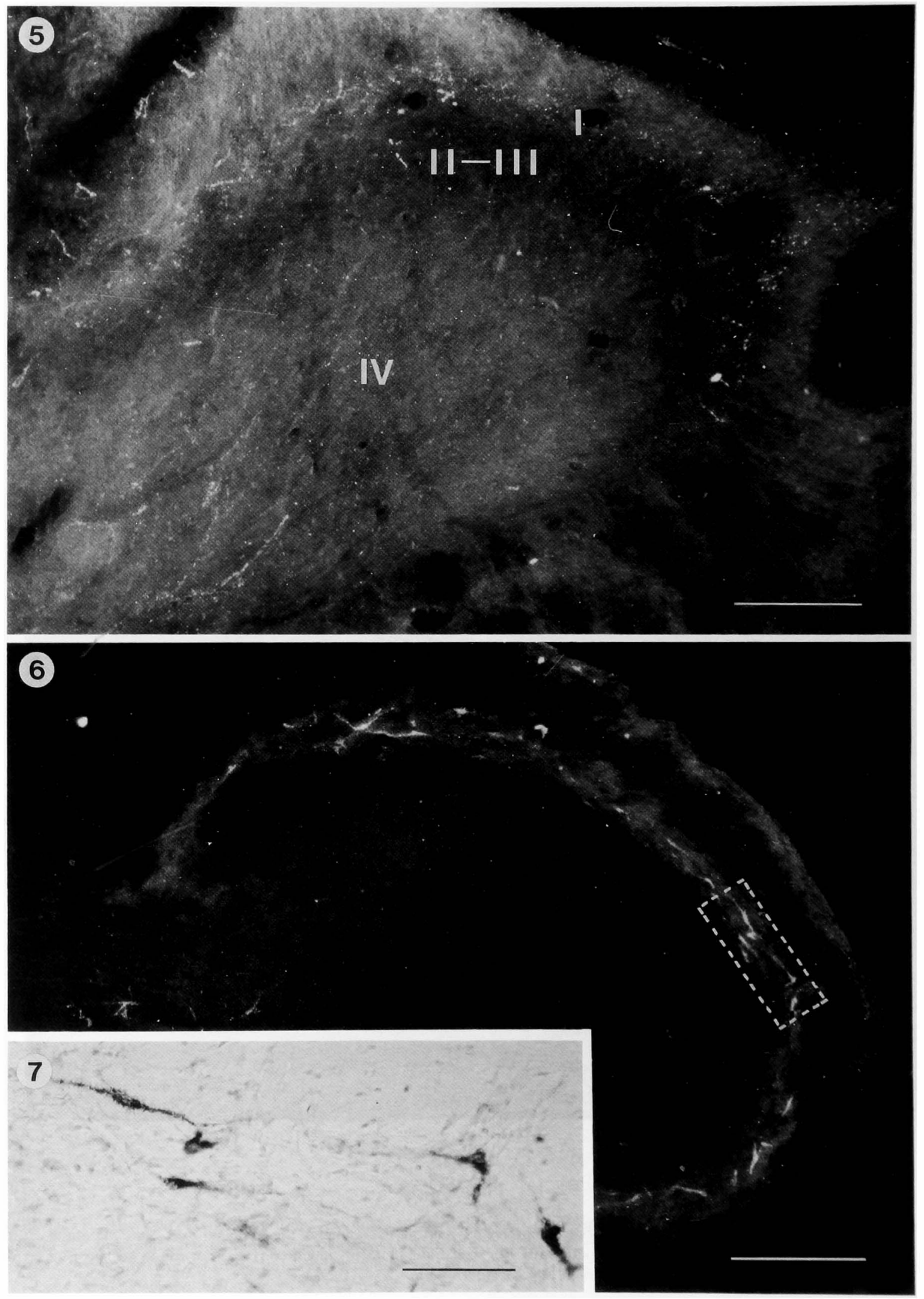
Plate IV

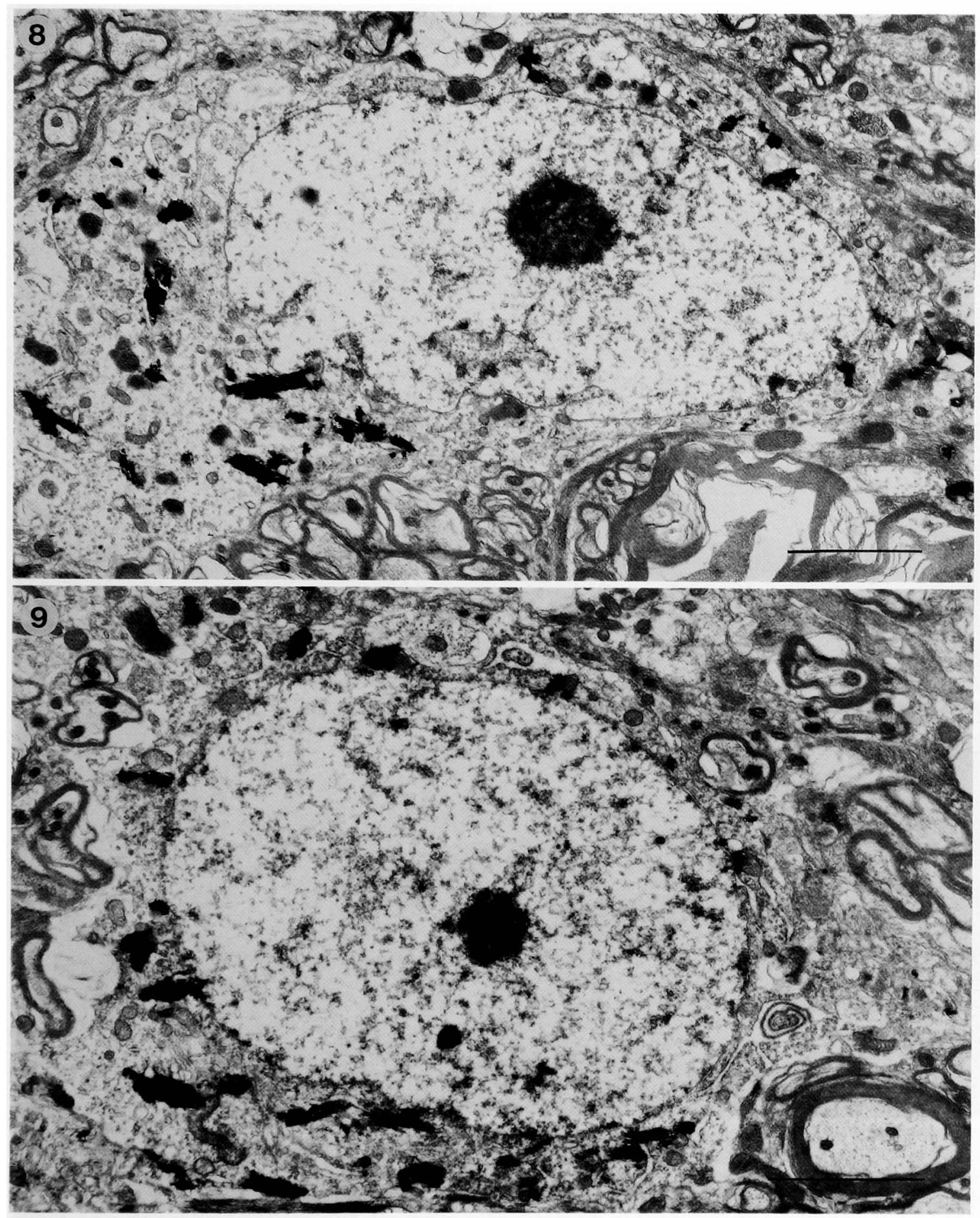

\section{Plate IV}

Figs. 8 and 9. Electron micrographs of spinoparabrachial projection neurons in lamina $\mathrm{I}$ of the $\mathrm{C} 1$ spinal cord. Note that these neurons contained electron-dense HRP reaction products in cytoplasm and had deeply indented (Fig. 8) or round nucleus (Fig. 9) with centrally located nucleolus. Calibration bars in Figs. 8 and $9=3 \mu \mathrm{m}$. 

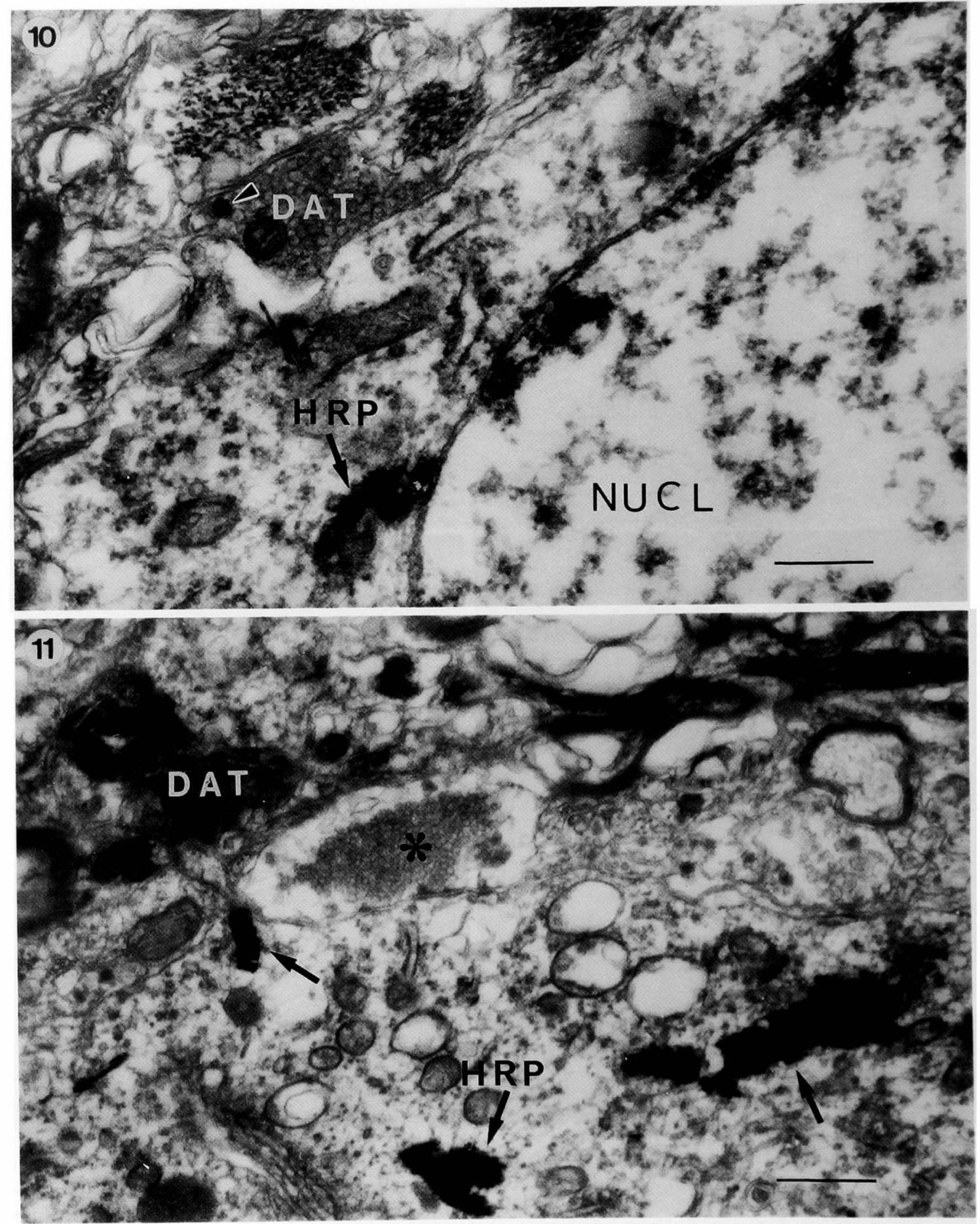

Plate V

Figs. 10 and 11. Electron micrographs of degenerating axon terminals making synaptic contacts with HRP-labeled ncurons (Figs. 10 and 11). Note that a few terminals were classified as the light type which was characterized by accumulation of small vesicles in light matrix (asterisk). Arrows and arrowhead indicate HRP reaction products in cytoplasm and large dense corcd vesicle in degenerating axon terminal, respectively. Calibration bars in Figs. 10 and $11=0.5 \mu \mathrm{m}$. 
Plate VI
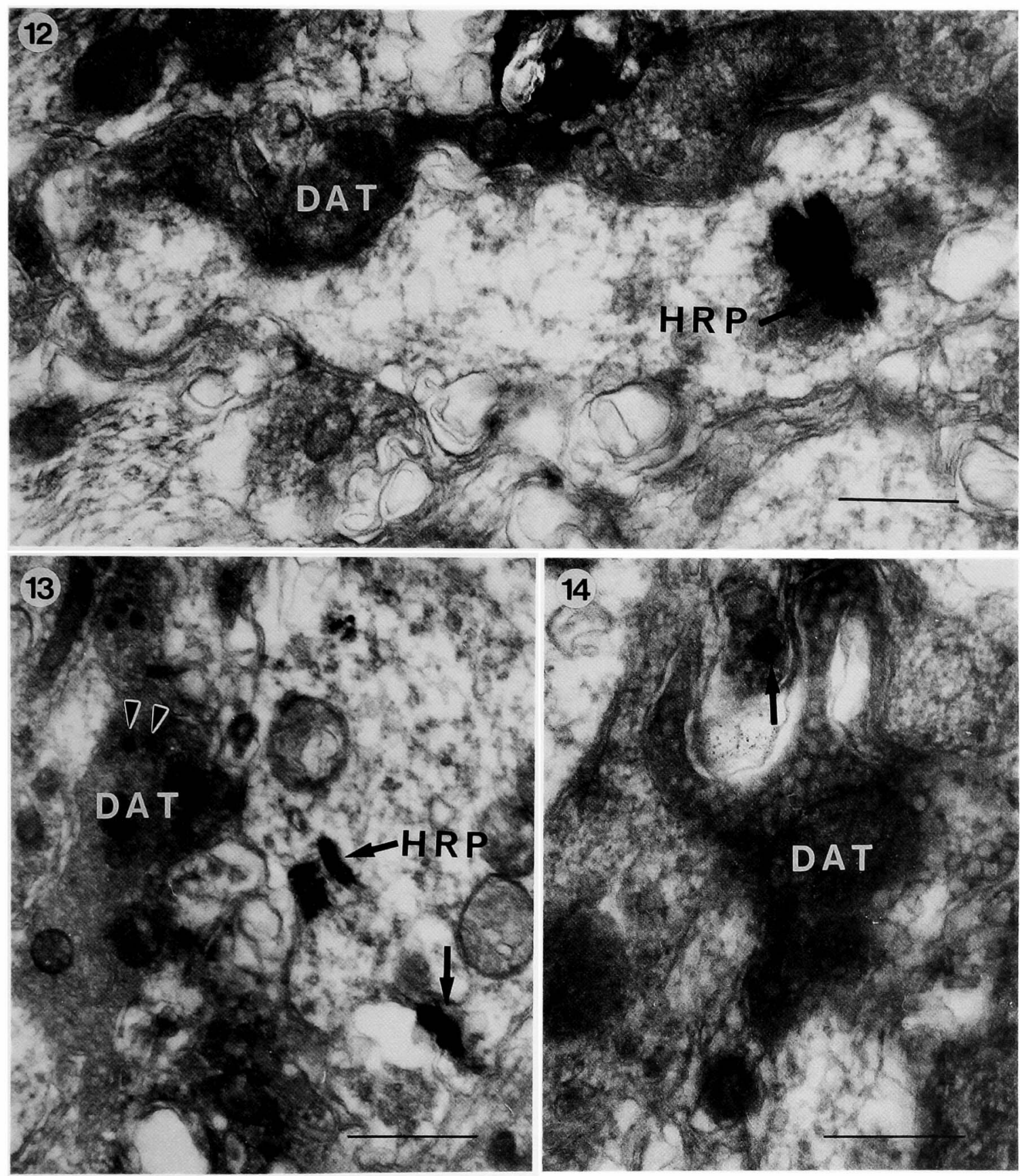

\section{Plate VI}

Figs. 12-14. Electron micrographs of degenerating axon terminals making synaptic contacts with HRP-labeled dendritic profiles (Figs. 12 and 13) and spine-like protrusion (Fig. 14). Arrows and arrowheads indicate HRP reaction products and large dense cored vesicles, respectively. Calibration bars in Fig. $12=1 \mu \mathrm{m}$, Figs. 13 and $14=0.5 \mu \mathrm{m}$. 